\title{
História e Região: Inovação e industrialização na economia salineira fluminense. ${ }^{1}$
}

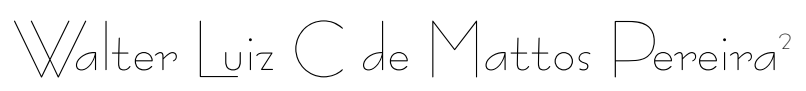

A Lagoa de Araruama, de águas salgadas, no litoral fluminense, foi uma valorosa fonte de extração de sal e de conchas. As conchas transformadas em calcário constituíam-se matéria prima para a fabricação de cal, soda cáustica e barrilha, insumos fundamentais na fabricação de vidros, material de limpeza e higiene, papel e outros produtos químicos derivados. Não obstante a importância das culturas do café e da cana-de-açúcar, a economia fluminense tinha no sal um de suas principais atividades econômicas. Espaço econômico distinto do Vale do Paraíba ou dos Campos dos Goytacazes, a Baixada Litorânea configura-se como um objeto de observação relevante no processo de industrialização fluminense.

A intensificação da produção salineira no Rio de Janeiro, a partir do século XIX, e, singularmente, na primeira metade do século seguinte, redimensionou as redes de produção e comercialização do sal. A reboque da atividade extrativa salineira, a busca por certa autonomia na fabricação de produtos químicos no Brasil, em destaque a soda cáustica

\footnotetext{
${ }^{1}$ Esse trabalho tem por base a pesquisa a tese de doutorado Cabo das tormentas e vagas da modernidade: uma história da Companhia Nacional de Álcalis e de seus trabalhadores. Cabo Frio (1943 - 1964) Arraial do Cabo, defendida como tese de doutoramento, no Programa de Pós-graduação em História da Universidade Federal Fluminense, Niterói, RJ, em maio de 2009, sob orientação do professor Marcelo Badaró Mattos.

${ }^{2}$ Professor Adjunto de História Econômica, Departamento de Fundamentos de Ciências da Sociedade, do Instituto de Ciências da Sociedade e Desenvolvimento Regional, da Universidade Federal Fluminense, em Campos dos Goytacazes, RJ. 
História e região: inovação e industrialização na economia salineira fluminense...

e a barrilha, acelerou a implantação de unidades industriais para a produção de derivados do sal e do calcário extraídos da Lagoa de Araruama. Se no início do século XX a região contava com sessenta e cinco estabelecimentos salineiros, em 1930 havia cento e vinte salinas ao redor da laguna, entre os municípios de Cabo Frio, São Pedro da Aldeia e Araruama. Algumas salinas ofereciam técnicas inovadoras frente ao processo artesanal da extração do sal, com seus cataventos, limitadas às condições naturais de secagem ao sol e ao vento. Surgem daí, nos anos 1950, a conversão tecnológica da Companhia Salinas Perynas, a instalação da Refinaria Nacional do Sal - RNS e a criação da Companhia Nacional de Álcalis - CNA, todas localizadas em Cabo Frio. As duas primeiras produziriam sal por combustão, em instalações a vácuo, a partir da salmoura previamente concentrada em tanques repletos de águas da Lagoa. A CNA produziria barrilha, produto do qual o Brasil dependia, para atender a indústria nacional de transformação. Ainda assim, a reconfiguração do parque salineiro em bases mais avançadas, mantinha as formas rudimentares de produção nas velhas salinas.

A paisagem fluminense era híbrida. Nas retaguardas das terras de marinha, de onde se extraía o sal, havia uma dupla produção agrícola em áreas de plantio de café e de cana-de- açúcar, atividades dotadas de sazonalidades distintas em seus ciclos produtivos. Para Alberto Lamego ${ }^{3}$, a lavoura de café teria retardado a expansão da salicultura, uma vez que foi somente em decorrência da crise da economia cafeeira fluminense que os interesses mercantis voltaram-se para as águas salgadas da Baixada Litorânea. A sintonia entre o tempo e o espaço, que envolvia a economia do sal, da canade-açúcar e do café tendia a uma racionalização do trabalho de uma forma singular: na seca, dos planaltos e planícies, os trabalhadores desciam dos cafezais e dos canaviais para as bordas da laguna e vice-versa na época das águas. Nesses deslocamentos suas vidas consumiam-se entre a restinga e

${ }^{3}$ LAMEGO, Alberto Ribeiro. O homem e a restinga. Rio de Janeiro, Lidador, 1974. 
a cordilheira fluminense ${ }^{4}$. Mesmo depois do fim da escravidão, essas economias sustentavam-se sob formas distintas de organização do trabalho, incorporando a região à complexidade das relações sociais de produção.

Podemos argumentar, portanto, que a região não se reduz a um circuito fechado, submetida exclusivamente a condições naturais próprias, o que importa pensar a história regional como um objeto de análise ampliada. Torna-se instigante, assim, a proposição de Alberto Lamego, de que o desenvolvimento acentuado da extração de sal nas bordas da laguna tenha se acelerado em meados do século XIX, por uma suposta transferência de capitais mercantis dos cafezais para as salinas fluminenses. Tal afirmação permite-nos interrogar, se essas evidências intercomunicantes das economias fluminenses podem ou não estar relacionadas com o deslocamento de mão de obra entre elas. No século XIX, importantes negociantes fluminenses de escravos, tanto do Vale do Paraíba, quanto da região canavieira, estavam atuando fortemente nas áreas de salinas. Numa perspectiva mais recente, por exemplo, podemos destacar que a industrialização da região salineira fluminense a partir da década de 1950, possibilitou a formação de fortes ondas migratórias internas, notadamente originárias do Norte e Noroeste fluminense para os municipios que circundam a Lagoa. Esses fluxos migratórios persistiram em anos mais próximos, fruto de um processo de desindustrialização naquelas regiões do Estado do Rio de Janeiro. Todas essas questões reafirmam o sentido de que a região coloca-se em conexão com outras escalas, sem desprezar o que lhe é específico. Consoante, a região deve ser vista na sua dimensão plural $^{5}$, caracterizando-se como um lugar de destaque na análise do processo histórico. A luz dessa integração, a região salineira flumi-

\footnotetext{
${ }^{4}$ Idem.

${ }^{5}$ CUNHA, Alexandre Mendes, SIMÕES, Rodrigo Ferreira e PAULA, José Antônio de. História Econômica e regionalização: contribuição a um desafio teórico-metodológico. Trabalho desenvolvido a partir da pesquisa "Desenvolvimento urbano e formação do mercado interno em Minas Gerais: 1830/1930", do Núcleo de Pesquisa em História Econômica e Demografia do Codeplar/UFMG, com apoio da FAPEMIG. 
nense passa a fluir na sua complexidade, não devendo ser vista como um espaço autônomo, mas inserida numa dinâmica mais ampla em sintonia com o todo.

A partir dessa proposta, a região salineira fluminense apresenta-se como um laboratório para se pensar a coabitação entre processos históricos distintos, além de contribuir para destacar a conexão do tempo na relação com os lugares. Se a região se sujeita a limites espaciais, a história regional deve enfatizar a existência de tempos históricos múltiplos, convivendo numa mesma realidade ampliada, sem desconsiderar as condições orgânicas e autônomas que constituem o espaço em destaque. Tomar a história regional nesses parâmetros implica perceber o local e o regional como espaços de dinamização de relações de produção distintas. Segundo Agnaldo Barbosa, em um mesmo contexto, o "tempo do mundo", sob a perspectiva das relações sociais, não se realiza em toda a sua potencialidade, em decorrência de uma força superior atribuída ao capitalismo, que define as áreas privilegiadas. Se o historiador que generaliza a análise de um tema trabalha com a ideia de tempo único, o pesquisador que se volta para o local, o regional, procura captar na dinâmica histórica tida como geral, a temporalidade específica do espaço que estuda, ou o "tempo do lugar". Se assim não fizer, corre o risco de pensar o local que investiga descolado de sua concretude, de sua vivência histórica real, criando, assim, um artificialismo histórico ${ }^{6}$. Portanto, a proposta desse artigo é buscar por uma história regional que potencialize as singularidades locais, sem perder de vista sua inserção na totalidade. Assim, a região, ao aparecer como um lugar de mudanças e permanências, poderia oferecer chaves interpretativas para a história.

Nesse artigo, propomos que o desenvolvimento da indústria do sal fluminense e seus derivados incorporam particularidades que trazem contribuições para o estudo das relações do micro com o macro, ao propiciar uma análise

${ }^{6}$ BARBOSA, Agnaldo de Souza. A propósito de um estatuto para a história local: algumas reflexões; em: História e perspectiva-vols. 21 e 22. Universidade Federal de Uberlândia, jan/dez/1999. 
mais dinâmica das políticas econômicas setoriais e suas conexões com as mudanças locais observadas no processo de reestruturação do parque salineiro fluminense, a partir da intervenção do Estado, sem ignorar o envolvimento do poder politico na sua esfera local.

\section{O sal}

Após obter uma concessão de terras devolutas em área de marinha, feita por D. Pedro I, em 1828, o alemão Luís Linderberg, chegado ao Brasil em 1808, construiu a Salina Grande, em Perynas, Cabo Frio, primeira grande empresa produtora de sal no país. Após a morte de Lindemberg, a Salinas Perynas, em 1891, foi vendida ao Banco Comércio e Indústria do Brasil, e, posteriormente, transferida a um novo proprietário, José Caetano Jalles Cabral. Vinte anos mais tarde, Jalles Cabral venderia a Companhia Salinas Perynas para seu genro, o médico Miguel Couto, que, depois de reorganizar a empresa, passaria sua administração a Miguel Couto Filho. Dada a dinamização da produção salineira local, o governo da República autorizaria a Companhia Salinas Perynas, em 1929, a construir, em Arraial do Cabo, o Porto do Forno, além de uma linha férrea que levasse o escoamento da produção de sal até o porto, para a utilização de embarcações de maior calado, tornando mais ágil a comercialização do sal7 . Acentua-se, nesse caso, a transformação da região, movida por investimentos oriundos de uma acumulação gerada pelo próprio setor salineiro para a construção de uma infraestrutura moderna.

Os primeiros anos do século XX marcaram o incremento das áreas de extração a partir da vinda de salineiros portugueses da região do Aveiro e de Figueira da Foz, que asseguraram novos métodos de evaporação e cristalização solar nas salinas do litoral fluminense. Na verdade, essa imigração acelerou-se em função da Primeira Guerra Mundial, pela dificuldade na comercialização do sal português

${ }^{7}$ SAL - Informativo da Companhia Salinas Perynas - 50 anos - 1979. 
na Europa. Havia outros motivos para sustentar esse afã português pelas áreas de salinas, uma vez que, desde 1895, o sal fluminense já havia tomado impulso na produção para atender o mercado interno, animado pela suspensão da cabotagem estrangeira e pela imposição de tarifas protecionistas, em 1902. O impeto da atividade salineira fluminense fazia-se sentir pela experiência de salineiros portugueses ao colocarem em prática técnicas inovadoras de extração do sal, desconhecidas pela indústria extrativa local, contribuindo para o aumento dos niveis de produtividade.

Essas mudanças, entretanto, não seriam suficientes para expressar uma nova realidade social ao trabalhador de salinas "de pés e mãos dilacerados nos cristais" persistindo a imagem daquele que "arrasta com seus rodos e seus carros uma vida tão amarga quanto o sal. O atribulado mourejador das margens da Araruama que cria e leva sobre os robustos ombros uma nova acumulação de riquezas que surge na história econômico-social da laguna". "Além dos trabalhadores do sal, havia também os catadores de conchas da Lagoa, atividade árdua e penosa que ocupava boa parte da população local. Quando da criação da Companhia Nacional de Álcalis, em 1943, a quem ficaria reservado o monopólio da extração desse material, para a fabricação de produtos químicos alcalinos, a coleta de conchas foi bruscamente interrompida pelo governo. Sob protesto dos catadores, Getúlio Vargas decidiu retroceder e autorizá-los a manterem a atividade de prospectar o solo da Lagoa de Araruama, para catarem o material utilizado na fabricação de cal, calcário e outros derivados em pequenas indústrias do Estado do Rio de Janeiro. A exploração de recursos naturais em torno da Lagoa era imperativa à sobrevivência daquelas populações.

Geraldo Beauclair, ao elaborar estudos sobre a economia salineira fluminense, percebe que a indústria do sal consagrou-se como uma atividade econômica inserida na dinâmica do mercado interno, desde o final do século XVIII, pois "mobilizou milhares de pessoas, alterou nosso quadro de importações, gerou movimentos de imigração importantes $e$

${ }^{8}$ LAMEGO, Alberto Ribeiro. O homem e a restinga. Op. Cit. 
apresenta para os estudiosos das ciências humanas formas e tipologias de organização extremamente originais, haja vista as relações sociais de produção nelas existentes". ${ }^{9}$ Novos caminhos para tropeiros e novos canais de comunicação com o interior foram abertos, à procura de mercados circundantes à região ou até mesmo mais longínquos. Para além das áreas de grande extensão, Beauclair chama a atenção para a formação de pequenos produtores de sal, derivada de conflitos locais que possibilitaram a organização de uma produção "associativa" comunitária, no sentido de aumentar a comercialização do "excedente". Esses esforços foram percebidos pela atuação da Câmara Municipal de Cabo Frio, para ampliar a atividade mercantil em torno da produção salineira local. Para Beauclair, criou-se, portanto, na provincia fluminense, uma atividade resistente, em que se registravam, a partir dos últimos anos do século XIX, pedidos significativos de aforamento de terras devolutas na Região dos Lagos. ${ }^{10}$

José Marcello Giffoni ${ }^{11}$, analisando aspectos relacionados à produção salineira fluminense, em Cabo Frio, na primeira metade do século XIX, confirma a integração desse complexo salineiro na diversificada economia da Provincia do Rio de Janeiro, desde o início do século XIX, inserido na dinâmica do mercado interno, como já havia antecipado Geraldo Beauclair. Ao tecer referências ao trabalho de Ilmar de Mattos, Giffoni reafirma ser a região salineira parte integrante do universo maior da agricultura mercantil-escravista delimitada por aquele autor. ${ }^{12}$ Configurava-se, portanto, uma paisagem mais complexa da economia fluminense que fugia à exclusividade do par produtivo café e cana-de-açúcar.

\footnotetext{
${ }^{9}$ OLIVEIRA, Geraldo de Beauclair Mendes de. Sol sobre sal: das comunidades indígenas às organizações salineiras da Lagoa de Araruama, in: À Margem, Rio de Janeiro, Fronteira, 1993.

${ }^{10}$ Idem. Como contribuição a discussão sobre a indústria salineira no Brasil, ver, também, do mesmo autor, A Construção Inacabada: a economia brasileira, (1828-1860). Primeira Edição. Rio de Janeiro, Vício de Leitura, 2001.

${ }^{11}$ GIFFONI, João Marcello. Sal: um novo tempero do Império. Primeira Edição. Rio de Janeiro, APERJ, 2000.

${ }^{12}$ MATTOS, Ilmar R. de. O tempo saquarema. Primeira Edição. Rio de Janeiro, Access, 1985.
} 
A produção de sal no Rio de Janeiro atingiu expressivas proporções a partir do século XX. As novas técnicas de evaporação e cristalização solar multiplicaram a produção buscando atender, inclusive, as primeiras e insipientes indústrias de soda cáustica que tentavam instalar-se no Estado. Esse crescimento já vinha proporcionando a instalação de uma infraestrutura mais atraente na Região dos Lagos. Lentamente, a Estrada de Ferro Maricá - E.F.M., idealizada em 1887, pelo Barão de Inoã e por uma comissão de fazendeiros da região, avançava em direção aos municípios que circundavam a Lagoa, para cobrir o percurso de Niterói a Cabo Frio. Em 1902, a ferrovia chegaria a Maricá; em 1913, a Araruama, e um ano depois, a Iguaba Grande. Até 1911 a ferrovia pertencera a Companhia Lavoura e Colonização de São Paulo, ano em que seu controle acionário seria transferido para a francesa Compagnie General de Chemins de Fer dês Etats Unis Du Brésil, por um milhão e seiscentos mil contos, não sem vencer uma longa disputa com empresas de capitais ingleses que desejavam explorar a linha. ${ }^{13}$ Cabo Frio aguardaria, porém, alguns anos até a chegada da ferrovia, distante vinte e quatro quilômetros da derradeira estação de Iguaba Grande. Para integrar a cidade à ferrovia foi preciso organizar um sistema de transporte lacustre em barcas mistas que transportavam passageiros e uma carga bastante diversificada, até a última estação da E.F.M. A ferrovia do sal, ao conectar-se com as linhas lacustres de navegação que percorriam o interior da Lagoa de Araruama estabeleciam um tipo de transporte modal que facilitava de forma substancial o escoamento da produção salineira e de outros produtos. Para além das estações ferroviárias concentradas nas principais cidades ou lugarejos, as composições chegavam às bordas da lagoa para receber o sal das embarcações,

\footnotetext{
${ }^{13}$ COSTA, Rosangela Valadão. Memórias do Velho Trem: ferrovia e sociedade na Região dos Lagos. Monografia de Conclusão do Curso de História, Universidade Veiga de Almeida, campus Cabo Frio, RJ, 2004. Ver também, SANTOS, Schneider Franco dos. Estação do sal: o trem de ferro em Cabo Frio (1910 - 1960). Monografia de Conclusão de Curso - História. Universidade Veiga de Almeida, campus Cabo Frio, 2004. Os dois trabalhos foram orientados pelo autor.
} 
grande parte, movidas a vela, por força eólica. Assim foi até 1937, quando a cidade de Cabo Frio seria alcançada pela via férrea, depois de cruzar São Pedro da Aldeia. A rota da Estrada de Ferro Maricá era a rota do sal. Além do sal, pelo caminho de ferro eram transportados os seguintes produtos: cal, areia, resíduos de salinas como o gesso, e mais, couro, aves, ovos, porcos, algodão, urucum, peixes e frutos do mar. Posteriormente, a E.F.M. seria incorporada à Estrada de Ferro Central do Brasil e por último à Estrada de Ferro Leopoldina, integrante da malha da Rede Ferroviária Federal $\mathrm{S} / \mathrm{A}$., acabando por ser uma das primeiras ferrovias a serem extintas no país, totalmente desmontada em 1964. A conexão entre os meios de transportes envolvidos no escoamento do sal implicava uma ação modernizante para a economia salineira.

As condições que vinham sendo criadas para impulsionar o complexo salineiro da Região dos Lagos não conseguiam aplacar os conflitos de interesses entre produtores e negociantes do sal que atuavam na praça local e no Rio de Janeiro. A reclamação dos produtores ia desde a ação predatória dos grupos mercantis à falta de crédito para o setor, passando pelo atraso na finalização das obras da ferrovia e nas suas constantes interrupções. Esses embaraços dificultavam os donos de salinas de se libertarem das teias de um mercado atacadista monopolista, controlado pelos comissários do sal. Do conflito entre esses grupos, coube ao grupo mercantil assumir a dianteira, impondo seus interesses ao fundar o Centro de Comércio do Sal Fluminense Ltda., na década de 1930.

$\mathrm{Na}$ arena de lutas, o Centro, como representante da classe mercantil, enfrentava os produtores pelo controle dos preços do sal. Esses atritos eram uma clara demonstração de que a produção salineira não fugia aos modelos que explicam as disputas que havia no circuito produtor/mercador de outras áreas expressivas da produção agrícola fluminense. Os principais atacadistas do produto na cidade do Rio de Janeiro representavam a fração hegemônica do grupo mercantil no Centro do Comércio do Sal, que garantiam, através do re- 
História e região: inovação e industrialização na economia salineira fluminense...

gulamento da instituição, regras muito próprias para definir os preços do produto. Nessas condições, Lamego ressaltava que o Centro utilizava dispositivos contratuais que "transcendiam as maravilhas do liberalismo econômico". Assim, o controle do abastecimento de sal pelo Centro colocava empecilhos aos ganhos, principalmente, da pequena indústria extrativa, que, para conseguir colocar seu sal no mercado, deveria unir-se aos interesses dos grandes produtores, com maior força de barganha junto ao grupo mercantil hegemônico.

A atuação do Centro do Comércio do Sal Fluminense provocava debates acalorados. Lamego afirmava que a instituição expressava os interesses de grupos monopolistas a frente das grandes firmas atacadistas de sal, forçando os salineiros a negociarem exclusivamente com elas. Segundo ele, "tratava-se de uma desmedida voracidade capitalista, do chorado liberalismo que permitia monopólios draconianos de parasitas inteiramente alheios à produção"14. A favor da atuação do Centro estava Paulo Guedes Alcoforado, que via como injusta a acusação de formação de truste, por parte dos atacadistas. Para ele, o Centro surgira como uma espécie de salvador da indústria salineira, pois, sem a sua atuação, as salinas não poderiam sequer funcionar. Alcoforado distribuía elogios ao Centro, pois, sem a sua intervenção, os salineiros estariam condenados à falência pela falta de recursos. ${ }^{15}$ Constata-se, dessa forma, uma relação de dependência dos produtores ao capital mercantil. É preciso, portanto, investigar como esses capitais financiavam a produção salineira, por quais mecanismos, questão não posta pelos dois autores em destaque. Nessa conjuntura, para a produção salineira fluminense, nas primeiras décadas do século XX, ainda estava implícito o domínio da circulação sobre a produção, numa economia capitalista que ainda guardava focos de resistência na sua transição.

\footnotetext{
14.LAMEGO, Alberto Ribeiro, O homem e a restinga. Op. Cit.

${ }^{15}$ ALCOFORADO, Paulo Guedes. O sal fluminense. Niterói, 1936 - p. 86/87
} 
Por outro lado, o Centro encontrava nas municipalidades um entrave à maximização dos lucros pelos comerciantes atacadistas, dada a expressiva carga tributária imposta, em especial, sobre a circulação. A descentralização do poder na Primeira República colocara o município num cenário ímpar, pouco estudado pela historiografia brasileira, na organização da base tributária que incidia sobre a produção e a circulação de mercadorias e na destinação orçamentária desses recursos ${ }^{16}$. Os impostos cobrados pelas prefeituras, além de reduzir as margens de ganho do comércio do sal, eram tidos como um facilitador da entrada do similar estrangeiro, pela intervenção no preço final. Ainda assim, os municipios eram ávidos em recolher tributos sobre o produto, em leis e códigos aprovados pelas câmaras municipais. A receita tributária sobre o sal, registrada no Balancete de Receitas e Despesas do Municipio de Cabo Frio, para a década de 1920, chegava a bater um indice de quarenta e dois por cento das receitas totais arrecadadas ${ }^{17}$. Na década de 1930, esses percentuais chegariam a cinquenta por cento da arrecadação total ${ }^{18}$. Muito embora, em valores absolutos, os grandes produtores contribuíssem mais, a cobrança era indistinta, aplicada em mesmos patamares aos pequenos salicultores. Uma análise das resoluções da Câmara Municipal de Cabo Frio, de 1936, deixa transparecer o quanto o sal mostrava-se como o principal produto que agregava recursos ao orçamento. As "taxas por saco", fixadas desde 1919, foram majoradas de cem réis, em 1936, para duzentos e dez réis, em 1947. Cumulativamente à taxa cobrada em valores absolutos, a resolução estabelecia a coexistência com um imposto "ad-valorem" de $2 \%$ sobre o valor da saca de $70 \mathrm{Kg}$, tomando como referência a cotação do sal na praça de Cabo Frio.

\footnotetext{
${ }^{16}$ As áreas de ocupação por salinas chegavam a aproximadamente, 19 milhões de metros quadrados, com uma produção estimada em 80 mil toneladas de sal. A delimitação das áreas produtoras (em metros quadrados) estava composta assim: Cabo Frio (9.830.000); Araruama (6.170.000); e São Pedro da Aldeia (2.530.000). A produção distribuia-se da seguinte forma: Cabo Frio, 39.417 mil toneladas; Araruama 21.371 mil toneladas; e São Pedro da Aldeia 9.569 mil toneladas. Fonte: LAMEGO, Alberto. O homem e a restinga. Op. Cit.

${ }^{17}$ Documento publicado no jornal "A Razão" de junho de 1928.

${ }^{18}$ Resolução no ${ }^{\circ} 13$ de 25.11.1936 da Câmara Municipal de Cabo Frio. Fundo de Arquivo Documentos Ancestrais - documentos 67, 100 e 101. Atas da Câmara Municipal de Cabo Frio. Arquivo Histórico da Câmara Municipal de Cabo Frio. 
Embora esses recursos fossem destinados, em teoria, à melhoria das condições sociais básicas da população local, como previa o Código Tributário Municipal de 1947, na prática, boa parte deles retornava aos setores economicamente expressivos da sociedade, sensivelmente, àqueles recursos destinados à manutenção de escolas e hospitais particulares, além de outras instituições privadas. Logo, uma boa parcela desse montante arrecadado era invertida em beneficio da própria classe produtora. Ainda que uma parte fosse destinada a empreendimentos públicos ou de caráter " $h u$ manitário", como previa o Código, essa parcela substancial, com certeza, estava longe de alcançar os setores excluídos da sociedade local. De toda a forma, os recursos tinham prevista sua alocação em calçamento de ruas, construção de escolas, melhoramentos urbanos, construção do matadouro municipal, construção do mercado municipal, não sem distinguir a subvenção às escolas particulares Sagrado Coração de Jesus, Santa Therezinha e Lídia Shermam e ao Hospital Santa Izabel. Nota-se, portanto, que mesmo depois do Estado Novo, a centralização política não limitava a ação dos municipios em constituírem-se de certa autonomia, ao definirem a destinação dos recursos da base tributária local sobre a produção e circulação de mercadorias, que, na maioria das vezes, reproduzia os interesses dos grupos socialmente privilegiados. ${ }^{19}$

Ainda que sujeitos ao arbitramento politico local, em relação à política fiscal, os produtores e negociantes do sal tentariam acomodar suas principais divergências com a criação, por Vargas, do Instituto Nacional do Sal - INS, em 10 de junho de 1940. O Estado pós-1930 surgiria como mediador e regulador de setores representativos da economia brasileira, com a criação de agências voltadas para a produção e a comercialização do açúcar, do café, do pinho, da borracha, entre outros. A medida, em princípio, provocou um duro golpe no Centro do Comércio do Sal Fluminense pela imposição

${ }^{19}$ Código Tributário Municipal de 1947 - Atas da Câmara Municipal de Cabo Frio - Arquivo Histórico. 
da produção por cotas, que passariam a ser disputadas com os grupos salineiros do Nordeste do país. Por outro lado, o INS teria a função de trabalhar na execução de projetos de inovação tecnológica para fortalecer o setor salineiro e dos derivados do sal.

Henrique Nogueira, empresário salineiro local, em artigo publicado em um jornal de Cabo Frio, chegou a dizer que, em princípio, o Instituto poderia ser visto como uma "tábua para o náufrago em pleno oceano", inspirando confiança, principalmente nos pequenos produtores, para cessar as refregas entre estes e os grandes comerciantes. O INS teria surgido num quadro de adversidades que a indústria salineira vinha enfrentando: desequilíbrio entre a produção e o consumo, instabilidade de preços, interesses regionalistas em choque, lutas pelo monopólio comercial, entre outros. Sobressaía, nesse contexto, o confronto entre o pequeno e o grande produtor, entre esse último e o atacadista do sal, especialmente quanto ao controle do transporte do sal que ficava concentrado nas mãos dos grandes produtores que tutelavam os pequenos e médios. Seriam necessários investimentos e suporte técnico aos pequenos, para que pudessem superar os métodos rudimentares de produção e furar o bloqueio imposto pelos grandes grupos do complexo produto/ mercador.

Contudo, o esforço do INS em mudar a paisagem da indústria salineira fluminense não oferecia nenhuma proposta consistente às cento e dezenove salinas do Rio de Janeiro, que contribuíam com Cr\$ 5 milhões para os cofres da autarquia. No estado do Sudeste, a maioria dos salineiros ainda subordinava-se a um grupo de três ou quatro empresários que controlavam o comércio do sal. Para a maior parte desses salineiros, até então, pouco havia sido feito, pelo INS, para modernizar o parque salineiro local. Subsistiam, portanto, as inovações realizadas nos anos iniciais do século XX. Para Henrique Nogueira, a indústria extrativa do sal vivia tempos deprimentes, pois todos os olhos e recursos do 
História e região: inovação e industrialização na economia salineira fluminense...

INS dirigiam-se "ao sonho cor de rosa da Álcalis". ${ }^{20}$ A reclamação procedia, pois as ações para o desenvolvimento do projeto de construção da Companhia Nacional da Álcalis CNA ocupavam a agenda do INS. Os recursos recolhidos pelos salineiros ao Instituto, relativos às contribuições sobre a produção de sal, no lugar de serem invertidos no fomento e na inovação da produção salineira local, vinham servindo de lastro às operações de empréstimos do INS junto ao Banco do Brasil, para compor o capital inicial necessário à criação da CNA. ${ }^{21}$ Nesses termos, para os empresários do sal, o INS constituiu-se como uma agência de Estado que, no lugar de resolver os problemas inerentes ao setor salineiro, garantia, com capitais privados, a constituição da CNA, retirando o foco dos investimentos necessários à regulação da produção local.

Em todo o caso, foi através do INS, que o governo passou a baixar diretrizes para a modernização da indústria salineira e de álcalis sódicos com o intuito de dotar o setor de um parque produtivo avançado. O Instituto ficara responsável por regular a produção, a comercialização, cuidando do abastecimento interno, inclusive da necessidade de importação ou não do produto. Além do mais, o INS deveria propor soluções e estabelecer as bases para a criação de uma indústria brasileira de álcalis sódicos no Brasil. ${ }^{22}$ Cabe registrar, portanto, que o INS não estava envolvido, exclusivamente, na questão do sal, pois parte de suas atribuições estava voltada ao planejamento e a execução de políticas voltadas para setores afins, como a produção de determinados produtos químicos derivados do sal.

\footnotetext{
${ }^{20}$ NOGUEIRA, Henrique. O Instituto Nacional do Sal e o problema salineiro do Rio de Janeiro, em: "A Razão", Cabo Frio, 30 de março de 1947, ano XVII, n" 22.

${ }^{21}$ Idem.

${ }^{22}$ Decreto-lei 5648 de 20 de julho de 1943.
} 


\section{Os álcalis sódicos: soda cáustica e barrilha}

No início do século XX, determinados setores da indústria de transformação mostravam-se incomodados com a dependência do Brasil de alguns produtos químicos importados, como os álcalis sódicos. O Congresso de Engenharia realizado no Rio de Janeiro, em 1901, assumiria uma defesa nacionalista e protecionista para a indústria de base brasileira, na tentativa de fomentar a produção nacional extrativa. Rodrigues Alves, por exemplo, apoiava a participação do Estado no incentivo ao desenvolvimento industrial, embora fosse contrário à intervenção direta na esfera econômica. Segundo Nícia Vilela da Luz, inúmeras empresas envolvidas na exploração de recursos naturais, após a Primeira Guerra Mundial, foram beneficiadas com empréstimos, créditos especiais, redução de impostos, redução de fretes, apoio para a construção de instalações etc. Entre essas empresas, a autora cita: Usina Esperança, Companhia Siderúrgica Mineira, Companhia Carbonifera Riograndenese, Companhia Norte Paulista de Combustiveis, Companhia Eletro Metalúrgica Brasileira, Companhia Siderúrgica Belgo Mineira. Outro presidente, Arthur Bernardes, também, encaminharia ao Congresso Nacional mensagens favorecendo os setores ligados ao cimento, a borracha e a soda cáustica. ${ }^{23}$

As dificuldades em dispor desses produtos, especialmente da soda cáustica e da barrilha, deixavam instáveis alguns setores industriais como os fabricantes de vidro, de tecidos, de papel e de produtos para higiene e limpeza. Para contornar o problema, o governo instituiu, em 1918, uma política de incentivo à instalação de pequenas unidades voltadas, em primeiro lugar, para a fabricação de soda cáustica ${ }^{24}$. Às três primeiras fábricas que se instalassem no país seria concedido um financiamento a juros subsidiados até o limite de dois mil contos, para atender às obras iniciais, valor que correspondia a setenta e cinco por cento do total orçado para

\footnotetext{
${ }^{23}$ Luz, Nicia Vilela da. A luta pela industrialização no Brasil. São Paulo, Alfa Omega, 2004, pp. $186-199$.

${ }^{24}$ Decreto n ${ }^{\circ} 12921$, de 16 de março de 1918. 
o empreendimento. ${ }^{25} \mathrm{O}$ empréstimo teria prazo de dez anos, amortizado em parcelas iguais que seriam exigidas a contar da data de inauguração da fábrica. Das onze empresas que se habilitaram, três foram selecionadas, sendo que apenas uma delas conseguiu dar conta do projeto. A A. F. Santos \& Cia., que se transformou posteriormente na Companhia Brasileira de Produtos Químicos, construiu a primeira fábrica de soda cáustica no Brasil, na localidade de Engenho da Pedra, em Inhaúma, no Rio de Janeiro, dotada de instalações modernas e capacidade para produzir cinco toneladas anuais do produto, a partir de $1923^{26}$. Portanto, iniciativas como essa só foram possiveis com incentivos oficiais para fomentar a industrialização do país, preferencialmente de itens destinados à fabricação de bens de consumo não-duráveis. Mesmo assim, essas experiências eram limitadas e perdiam a força frente às investidas de trustes e cartéis internacionais. A fábrica de Inhaúma foi à falência por não suportar a concorrência internacional.

A segunda tentativa representaria uma ação mais concreta envolvendo capitais nacionais e estrangeiros para instalar uma indústria de soda cáustica de maior envergadura. No dia 17 de agosto de 1933, seria fundada a Companhia Eletro Química Fluminense, com parte dos investimentos vindos da Caixa Econômica do Rio de Janeiro. Para a conclusão dos negócios chegaria ao Brasil, pelo Zeppelin, Wilhelm Lehmann, químico alemão, diretor técnico da empresa Krebs \& Cia, de Berlim. ${ }^{27}$ Inicialmente a Companhia Eletro Química Fluminense teria uma capacidade de produção de

${ }^{25}$ Os juros definidos eram de cinco por cento ao ano

${ }^{26}$ O Fluminense, Niterói, Domingo, 7 de maio de 1961, ano LXXXII, $n^{\circ} .23933$, p. 8 - Acervo FBN

${ }^{27}$ O corpo societário da empresa era formado por Afonso Vizeu, Jose Alves da Motta (principal acionista), Aluízio de Oliveira Maia, Alaor Prata Soares, Antônio Malheiros Braga, Manoel Lopes Fortuna Junior, Manih Aboud, Antônio de Paula Affono, José Dias de Souza Brandão, Antônio Dias de Souza Brandão, Manuel Dias de Souza Brandão, Eduardo Alberto Seelig, Antônio Marques Ribeiro, Alfredo de Siqueira, Francisco Manoel Correa de Figueiredo Lima, Guilherme Guinle, Antônio Augusto Alves, Almiro Maia, João Pinto, Sociedade Industria e Comercial Schmuziger Ltda., Carlos Moura, Severino Pereira da Silva, Companhia Nacional de Cerâmica, Joaquim Penalva Santos e Raymundo Lullio Teixeira Mendes. 
aproximadamente mil toneladas anuais de soda cáustica. Com a inauguração da fábrica em Alcântara, no município de São Gonçalo, Rio de Janeiro, em 23 de maio de 1936, o parque industrial brasileiro poderia contar com uma indústria de base, para satisfazer algumas das grandes indústrias de transformação instaladas em São Paulo. ${ }^{28}$ Nesse rol encontrava-se a Klabim, as Indústrias Matarazzo e a Johnson \& Johnson, todas elas interessadas em suprir com produtos alcalinos suas respectivas linhas de produção. A Johnson \& Johnson mantinha uma pequena unidade de fabricação de soda cáustica no seu parque industrial destinada ao clareamento de algodão medicinal. A Klabim produzia baixas quantidades de soda cáustica para a fabricação de papel e celulose, em uma pequena usina que havia instalado no Paraná. As Indústrias Matarazzo chegaram a manter negociações com grupos americanos para montar uma unidade própria. ${ }^{29}$ Eram empresas líderes na fase inicial do processo de industrialização no Brasil e, sem dúvida, instavam o governo a apresentar ações políticas práticas para dotar a economia nacional de unidades fabris fundamentais ao desenvolvimento industrial.

Destacava-se também, nesse período, o empreendimento Saíra localizado na extremidade ocidental da Lagoa de Araruama, na praia do Hospício, no município de Araruama. O projeto, tocado pelo banqueiro Benedito Manhães Barreto, futuro diretor da Companhia Nacional de Álcalis - CNA, concebia uma fábrica de barrilha por um processo mais moderno, cuja produção era estimada em três mil toneladas anuais ${ }^{30}$. Tempos depois, apenas três pequenas fábricas funcionavam no Brasil. Nesse sentido, as primeiras décadas do regime republicano no país não seriam refratárias à ação do Estado em politicas voltadas para a industrialização nacional, destarte não contasse ainda com instituições específicas para criar condições à instalação dessas indústrias.

\footnotetext{
${ }^{28}$ O Fluminense, Niterói, 7 de maio de 1961, ano LXXXII, n. 23933, p.8.

${ }^{29}$ PINTO, Mário da Silva. A indústria de álcalis no Brasil: o projeto Cabo Frio. Rio de Janeiro, Ministério da Agricultura/DNPM/LPM, 1947.

${ }^{30}$ O Fluminense, Niterói, 09 de setembro de 1943, ano LXVI, nº 18580.

200 Revista de História Regional 15(2): 184-210, Inverno, 2010
} 
Segundo Eulália Lobo, havia apenas dez fábricas de cal no Rio de Janeiro, em 1908. O setor de produtos químicos e análogos ainda apresentava um nível baixo de capitalização e valor de produção, conforme o censo de 1907. Ainda assim, pode-se verificar, pelos dados apresentados pela autora, um forte aumento de estabelecimentos industriais destinados à fabricação de produtos que utilizavam a soda cáustica e a barrilha como matérias primas. A autora cita fábricas de vidros e cristais, produtos químicos propriamente ditos, fábrica de sabão, de papel, que surgiram a partir de 1910. Entretanto, Eulália Lobo não define o setor químico como sendo um setor primordial na constituição inicial de um parque industrial na capital da República e seus arredores. ${ }^{31}$

De um modo geral, das indústrias que se instalaram no país durante a Primeira República, algumas contavam com a participação de investimentos estrangeiros, embora modestos, resultantes da internacionalização do capital industrial dos países centrais, em destaque, os EUA. Porém, em certos setores, esses investimentos assumiram números significativos, principalmente, as empresas-líderes do capitalismo central, consideradas as inversões na indústria de transformação, como por exemplo, bens de consumo produzidos pelo complexo metal-mecânico, eletro-químico/farmacêutico, fornecedor de insumos, carnes industrializadas, produtos de toalete etc, ou ainda o setor de bens de produção como metais não-ferrosos, cimento, papel e borracha. Esses recursos faziam parte das estratégias de expansão dessas empresas, após esgotarem suas possibilidades de crescimento nos seus mercados internos de origem. Para Suzigan e Szmrecsányi, no Brasil, é possível identificar quatro dessas estratégias: processamento de matérias primas locais para exportação do produto final; obtenção da primazia em fornecer aos mercados locais; captura de potencial de crescimento no abastecimento do mercado interno; e aumento da

${ }^{31}$ LOBO, Eulália Maria Lahmeyer. História do Rio de Janeiro: do capital comercial ao capital industrial e financeiro. (vol. 2) Primeira Edição. Rio de Janeiro, IBMEC, 1978. 
participação no abastecimento do mercado interno. ${ }^{32}$ Nessa perspectiva, podemos considerar que a indústria de álcalis sódicos (soda cáustica e barrilha), controlada por grandes grupos internacionais, tinha baixa integração nesse elenco de estratégias, pois, para suprir o mercado interno, não restaram tentativas, na maior parte, frustrantes. Portanto, mostrou-se imprescindível, no caso da produção de produtos alcalinos, não obstante as regras do liberalismo vigente, a indução estatal para respaldar com incentivos à instalação dessas indústrias no país.

Tanto no caso da soda cáustica quanto da barrilha, os altos investimentos necessários e a ação dos grupos internacionais ligados à indústria química impediam a sobrevivência de unidades industriais nacionais que pudessem garantir o abastecimento de outras indústrias instaladas no país. A dependência do produto importado tornara-se ainda mais grave em face das dificuldades do comércio internacional durante a Primeira Guerra Mundial. Antes dos Estados Unidos assumirem a liderança no mercado, a partir da década de 1940, a Inglaterra era responsável por setenta por cento das importações brasileiras de produtos alcalinos. Essa situação forçou o governo a restabelecer uma política de amparo à produção nacional, embora tímida, por sugestão do Conselho Federal do Comércio Exterior.

Grupos internacionais monopolistas articularam-se. A norte-americana Du Pont, associada a outras empresas, estava interessada em prospectar salgema no litoral do Brasil, com o objetivo de explorar matéria prima necessária à produção de álcalis sódicos. Para mapear as possibilidades, seus técnicos percorreram o litoral do Rio Grande do Norte ao Rio de Janeiro. As condições principais para a instalação de uma fábrica dessa natureza seriam: sal em abundância e grande volume de água com temperatura adequada. A Du Pont, junto com a Imperial Chemical Industries - ICI,

\footnotetext{
${ }^{32}$ SUZIGAN, Wilson e SZMRECSÁNYI, Tamás. Os investimentos estrangeiros no início da industrialização no Brasil, in: SILVA, Sérgio e SZMRECSÁNYI, Tamas (orgs.). História Econômica da Primeira República. Primeira Edição. São Paulo, Hucitec/ABPHE/Edusp, 2002. pp. 261\283. 
constituíram a Duperial, no Brasil. A Duperial tentava associar-se a Companhia Salgema Soda Cáustica e Indústrias S/A - SALGEMA, para que aliada ao grupo belga Solvay, fundassem as Indústrias Brasileiras Alcalinas S/A - IBASA. Portanto, os três grupos internacionais mais poderosos no setor de álcalis sódicos controlariam a IBASA.

Enquanto a Companhia Nacional de Álcalis não vingava, o grupo acima avançava no seu propósito. No dia 15 de novembro de 1948, no Salão Nobre do Ministério da Viação e Obras Públicas, no Rio de Janeiro, foi assinado um documento representativo para a instalação de uma fábrica de produtos alcalinos no Brasil. Ali compareceram os representantes da SALGEMA, da CNA e da IBASA, para a assinatura de um convênio que permitira a utilização do salgema encontrado em regiões do Nordeste, para a fabricação de álcalis sódicos. Estavam presentes, além do Ministro Clóvis Pestana, o governador do Estado, Macedo Soares, deputados, senadores, militares e demais convidados. O coronel Bernardino de Matos Neto, ao louvar o acordo, recordava das tentativas sem êxito, para instalar uma fábrica de álcalis sódicos no Brasil.

A iniciativa de Antônio Fernandes dos Santos, lídimo pioneiro da implantação da indústria da álcalis no Brasil, deve-se à organização da Companhia Nacional de Indústrias Químicas que, em 1922, sob a orientação da Companhia Brasileira de Produtos Químicos, haveria de lutar contra o meio, ainda pouco afeiçoado a empreendientos dessa natureza... A despeito da haver paralisado seus trabalhos a 18 de julho de 1827 , essa Companhia deixou, além dos ensinamentos, o exemplo vivo da pertinácia de um homem na pessoa de seu filho, o Engenheiro Penalva dos Santos, quem, como que reverenciando a memória do pai, funda, em 1934, a Cia. Eletro-Química Fluminense, cuja fábrica inaugurada dois anos mais tarde, se mantém até hoje em pleno funcionamento... Saltando sobre o tempo, vamos encontrar nos dias que correm, três empresas na estaca zero da caminhada sedutoea: a Companhia Nacional de Álcalis, a Companhia Salgema Soda Cáustica e Indústrias Químicas e as Indústrias Brasileiras Alcalinas S/A. ${ }^{33}$

${ }^{33}$ O Observatório Econômico e Financeiro, Rio de Janeiro, ano XIII, $n^{\circ} 153$, outubro de 1948, pp. 113-118. 
Pelo contrato, a SALGEMA se comprometia a fornecer à CNA toda ou parte do sal necessária à industrialização da barrilha e da soda cáustica. Impressiona o fato da CNA participar como contratante, sem que sequer tivesse sido iniciada a construção da fábrica em Arraial do Cabo, emperrada por questões de natureza política e econômica. No fundo, o projeto em si, abriria os flancos para os cartéis e trustes internacionais, que, ao associaram-se a grupos nacionais, tentavam implodir a construção da CNA.

Ao insistir em reduzir a dependência em álcalis sódicos, o governo brasileiro voltaria a tomar algumas iniciativas, buscando de novo incentivar a abertura de mais indústrias, ao conceder um aporte de cinquenta por cento do capital necessário para constituição de empresas ligadas ao setor, mais uma vez sob a forma de financiamentos com juros reduzidos, aliados à prática de renúncia fiscal. Dos seis projetos apresentados apenas três foram selecionados. No entanto, o único empreendimento que se materializou foi o de uma empresa que sequer estava entre as três escolhidas, para montar uma fábrica de soda cáustica na Ilha do Governador. Após cinco anos de luta para estabilizar-se, a empresa acabou falindo, tendo que vender suas máquinas para a Companhia Eletro Química Fluminense. Logo na metade do século XX, era o seguinte o panorama brasileiro em relação à produção de álcalis sódicos: não havia fabricação de barrilha e as poucas empresas ativas estavam envolvidas apenas na produção de soda cáustica, em quantidades reduzidas, como a fábrica de São Gonçalo, que, ainda assim, sustentava um processo de fabricação primário. Quase a totalidade dessas experiências ficou reduzida ao Rio de Janeiro, pela proximidade das fontes de matérias primas exigidas na fabricação de álcalis sódicos, como o sal e o calcário, encontrados na região salineira do Estado. Pesava aí também a forte interveniência política de Amaral Peixoto, em querer dinamizar a indústria fluminense, com ênfase ao interior. 


\section{O sal e os álcalis sódicos na rota da industrialização.}

As vagas modernizantes da industrialização brasileira, nos anos 50, chegariam à economia salineira fluminense e ao setor da produção alcalina. O projeto nacional-desenvolvimentista fazia crer que a via da industrialização, seria a chave para a superação da fragilidade da economia brasileira e contribuir automaticamente para a superação dos imensos problemas sociais no país.

Como parte desse projeto, a Companhia Salinas Perynas, propriedade e administrada por Miguel Couto Filho, foi remodelada em 1952, no governo de Amaral Peixoto. Miguel Couto Filho viria a suceder o genro de Getúlio Vargas no governo do Estado do Rio de Janeiro, entre 1955 e 1958. A nova tecnologia possibilitou que a produção de sal do Rio de Janeiro dobrasse, passando de $3 \%$ para $6 \%$ da produção nacional. ${ }^{34}$ Independente das condições naturais, as instalações a vácuo despejavam 60 mil toneladas por ano de sal refinado de boa qualidade, em vez de dezoito mil toneladas de sal grosso produzidas anteriormente. ${ }^{35}$ A produção de sal atingiria um grau de desenvolvimento emblemático. Apoiada pelo governo, a empresa passou por uma modernização sem precedentes em suas instalações. Essa virada tecnológica significou um marco histórico na produção brasileira de sal. Até então, essa produção estava subordinada a um processo rudimentar de evaporação de águas salgadas nas salinas, sujeito a condições climáticas favoráveis, por meio de secagem natural. A tecnologia cambiante experimentava um novo sistema de processamento a vácuo, para transformar em sal as salmouras previamente concentradas nos tanques de evaporação. Essa mudança radical no processo de transformação da salmoura em sal destoava das outras centenas de salinas espalhadas ao redor da laguna. Independente disso, os moinhos de vento e os pés descalços dos trabalhadores do sal decifravam as estruturas arcaicas da produção local.

\footnotetext{
34 INS - Produção de sal no Brasil - Ano calendário de 1952 - Arquivo Nacional, Rio de Janeiro.

35 SAL - Informativo da Companhia Salinas Perynas - 50 anos.
} 
A Refinaria Nacional do Sal - RNS foi outra unidade a instalar-se em Cabo Frio. Posta a prova, a partir de 1953, sua produção destinava-se a suprir a falta de um sal refinado com alto teor de pureza, até então inexistente no país. As instalações foram importadas da Alemanha, da empresa Rud Otto Meyer, de Hamburgo, com capacidade de produzir 50 toneladas por dia, 16.500 toneladas por ano. Seu sal tendia a atender às necessidades do mercado interno, não só no que diz respeito ao consumo alimentar direto, como também para atender as indústrias alimentícias e farmacêuticas que careciam do produto de alta qualidade. A Sal Cysne passara a fortalecer, assim, a oferta de sal no país. ${ }^{36}$ Sua entrada em operação elevou a participação do Rio de Janeiro para

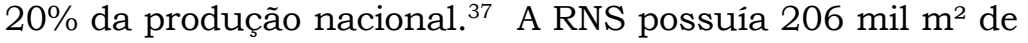
área de cristalização e a Companhia Salinas Perynas, 535 mil $\mathrm{m}^{2}$ de área similar. As duas empresas, ao colocarem em destaque a produção de sal fluminense, abriram caminho para que se ampliassem os niveis de produtividade do setor, possibilitando que um excedente gerado pudesse atender a demanda inicial de sal pela Companhia Nacional de Álcalis CNA, em Arraial do Cabo, para a produção de soda cáustica e de barrilha.

Os estudos para a criação da CNA foram feitos sob responsabilidade do Laboratório de Produção Mineral do Departamento Nacional de Produção Mineral do Ministério da Agricultura, resultantes no "Projeto Cabo Frio", apresentado no II $^{\circ}$ Congresso Brasileiro de Engenharia e Indústria, realizado em 1946. O projeto foi fruto do trabalho realizado pela Comissão de Estudos sobre a Indústria da Soda Cáustica, por recomendação do Conselho Federal de Comércio Exterior, sob supervisão do Instituto Nacional do Sal - INS. Essa Comissão encerrou seus trabalhos entre julho de 1942 e junho de 1943, com a participação de Mario da Silva Pinto, coordenador do Projeto; José Bretãs Bering, do Banco do Brasil; Fernando Falcão, José Franklin Veras Marques, Álvaro

\footnotetext{
${ }^{36}$ Refinaria Nacional do Sal - Informativo empresarial de 29.10.2004.

${ }^{37}$ INS - Produção de sal no Brasil - Ano calendário de 1953 - Arquivo Nacional, Rio de Janeiro. 
História e região: inovação e industrialização na economia salineira fluminense...

Veras e Francisco de Assis Gondim Menescal, do Instituto Nacional do Sal; e José Lopes Raimundo, da Universidade de Lisboa. O resultado final traduziu-se num relatório complexo que orientava o governo pela instituição de uma sociedade de economia mista com o controle acionário do Estado. Assim nascia a CNA.

O êxito da CNA dependeria do reconhecimento de três limitações e sua consequente superação: 1) a produção inicial da fábrica deveria ser de 50 mil toneladas de barrilha; 2) reconhecer que, ainda assim, essa quantidade ficaria aquém do volume importado pelo país; e 3) o artigo produzido no Brasil deveria concorrer vantajosamente com os preços externos controlados por trustes e cartéis internacionais. Em setembro de 1943, o "Observador Econômico e Financeiro" insistia que um dos capitulos mais importantes da economia brasileira, depois do fim da guerra, seria criar condições para o desenvolvimento do seu parque industrial. No entanto, a industrialização do país para ter assegurado o seu avanço, deveria, segundo o periódico, sair da fase de idealização e caminhar a passos largos para a fase de realização. O jornal especializado ressaltava que a industrialização do minério, do petróleo, da borracha, do alumínio, do níquel e dos álcalis criava produtos fundamentais "à defesa nacional e à vida humana". Nesse grupo, a barrilha e a soda cáustica eram considerados, segundo o jornal, o "pão da indústria". Era preciso ter claro que "a soda cáustica é o álcali alimentador direta ou indiretamente de toda a nossa organização fabril", dotando o Brasil "das eras do aço, petróleo e carvão e da soda cáustica." 38

Consciente da ação dos trustes e cartéis internacionais que colocavam em risco permanentea constituição da empresa, como mostramos nas páginas anteriores, o governo julgava que, apesar dos perigos, qualquer adiamento do projeto de instalação da CNA ameaçava de paralisação setores vitais da indústria brasileira. Assim, o governo Vargas decidiu criar a

${ }^{38}$ O Observador Econômico e Financeiro. Rio de Janeiro, n ${ }^{\circ}$, setembro de 1943 , ano VIII - pp. 95 - 102. 
CNA, em 1943, um projeto inserido na política de substituição de importações, que deixava patente a urgente necessidade do país ser autosuficiente na produção de álcalis sódicos, para avançar na industrialização. Inviabilizado em seus anos iniciais, a execução do projeto só pode ser posta em prática, a partir do segundo governo Vargas, em 1952, juntamente com a Companhia Salinas Perynas e a RNS. Sua viabilização somente seria possivel com a transferência de tecnologia francesa e a injeção de fundos públicos, com a participação do recém instalado Banco Nacional de Desenvolvimento Econômico - BNDE. Ainda assim, a CNA passaria por uma série de contratempos até a sua inauguração, em 1960, vivendo tempos dificeis e temerários.

\section{Conclusão}

A indústria extrativa fluminense de sal passou por uma série de transformações desde o início da sua exploração econômica. Foi possível ao sal, pela expansão das áreas de salinas, pela utilização de novas técnicas, pelo estabelecimento de uma infraestrutura, garantindo novos horizontes de comercialização, e pela dinamização industrial da Baixada Litorânea do Estado do Rio de Janeiro, assumir uma posição de destaque na economia fluminense junto com a cana-deaçúcar e o café.

Os primeiros movimentos implicavam nas disputas entre setores ligados a produção e a comercialização do sal. A garantia de recursos por parte dos atacadistas e negociantes do sal a serem disponibilizados aos produtores de sal, implicou em lutas internas que levaram a criação do Centro do Comércio do Sal Fluminense, posição hegemônica dos comerciantes açambarcadores do sal. A regulação do mercado salineiro, o controle dos preços, da produção e da comercialização, a partir da criação do INS, colocam o governo como um ator decisivo nas políticas voltadas ao setor, a partir do Estado Novo. 
História e região: inovação e industrialização na economia salineira fluminense...

O retorno de Vargas ao poder foi decisivo para a inovação e o desenvolvimento da indústria do sal e de álcalis sódicos no Rio de Janeiro. O Estado como agente indutor de mudanças, possibilitou a instalação de três unidades industriais, duas privadas e outra estatal, respectivamente, a Refinaria Nacional do Sal, a Companhia Salinas Perynas e a Companhia Nacional de Álcalis. Dessa forma, a tentativa de industrialização e modernização do setor denota a ideia de um projeto nacional-desenvolvimentista em operação.

\section{História e Região: Inovação e industrialização na economia salineira fluminense}

Walter Luiz C de Mattos Pereira

Resumo: O artigo pretende retomar a história da indústria extrativa do sal e de seus derivados na Região dos Lagos, no Rio de Janeiro, tema pouco estudado pela historiografia. Cabe ressaltar que a produção salineira fluminense desde o século XIX expressava junto com o café e a cana-de-açúcar um dos principais itens da economia fluminense. No segundo governo Vargas, as antigas salinas iriam conviver com a reestruturação do parque salineiro, em face da remodelação e implantação de novas empresas, com o apoio do Estado, como a Companhia Salinas Perynas e a Refinaria Nacional do Sal, imprimindo mudanças na paisagem regional. Para superar a dependência ao produto importado e a frágil indústria de álcalis sódicos no país, cuja material prima básica era o sal, o esforço maior resultaria da criação na Companhia Nacional de Álcalis - CNA, como parte do projeto nacional-desenvolvimentista.

Palavras-chaves: História Regional; História Econômica; História de Empresas; História e Desenvolvimento Econômico. 
Abstract: The article aims to understand the history of salt mining industry and its derivatives in the Região dos Lagos, in Rio de Janeiro, little researched by historiography. It is noteworthy that the salt production from the nineteenth century expressed along with coffee and sugar cane a major item in the "fluminense" economy. In the second Vargas government, the old salts would live with the restructuring of the salt park, due to the redesign and deployment of new businesses, with the support of the State, as the Companhia Salinas Perynas and the Refinaria Nacional do Sal, printing changes in the regional landscape. To overcome the dependence on imported product and the fragile sodium alkalis industry in the country, whose basic raw material was salt, the biggest effort would result in the construction of Companhia Nacional de Alcalis - CNA, as part of "nacionaldesenvolvimentista" project.

Keywords: Regional History; Economic History; Enterprise History and History and Economic Development.

Recebido: $13 / 07 / 2010$

Aprovado:08/08/2010 